\title{
Geospatial Trends and Decadal Anomalies in Extreme Rainfall over Uganda, East Africa
}

\author{
Charles Onyutha \\ Faculty of Technoscience, Muni University, P.O. Box 725, Arua, Uganda \\ Correspondence should be addressed to Charles Onyutha; conyutha@gmail.com
}

Received 28 July 2016; Revised 4 November 2016; Accepted 10 November 2016

Academic Editor: Efthymios I. Nikolopoulos

Copyright ( 2016 Charles Onyutha. This is an open access article distributed under the Creative Commons Attribution License, which permits unrestricted use, distribution, and reproduction in any medium, provided the original work is properly cited.

\begin{abstract}
Trends and variability in series comprising the mean of fifteen highest daily rainfall intensities in each year were analyzed considering entire Uganda. The data were extracted from high-resolution $\left(0.5^{\circ} \times 0.5^{\circ}\right)$ gridded daily series of the Princeton Global Forcings covering the period 1948-2008. Variability was analyzed using nonparametric anomaly indicator method and empirical orthogonal functions. Possible drivers of the rainfall variability were investigated. Trends were analyzed using the cumulative rank difference approach. Generally, rainfall was above the long-term mean from the mid-1950s to the late 1960s and again in the 1990s. From around 1970 to the late 1980s, rainfall was characterized by a decrease. The first and second dominant modes of variability correspond with the variation in Indian Ocean Dipole and North Atlantic Ocean index, respectively. The influence of Niño 3 on the rainfall variability of some parts of the country was also evident. The southern and northern parts had positive and negative trends, respectively. The null hypothesis $H_{0}$ (no trend) was collectively rejected at the significance level of $5 \%$ in the series from 7 out of 168 grid points. The insights from the findings of this study are vital for planning and management of risk-based water resources applications.
\end{abstract}

\section{Introduction}

The changes in weather conditions seem to alter the frequency and severity of water disasters from their normal occurrences in different parts of the world. Importantly, extreme rainfall events are directly relevant for planning and management of risk-based hydrometeorological applications. In the same line, several studies have been conducted on extreme rainfall in various parts of the world including Bangladesh [1], Peninsular Malaysia [2], Montenegro [3], Western Germany [4], Philippines [5], Eastern and Central Tibetan [6], Georgia [7], Southern and West Africa [8], Iran [9], and Caribbean Region [10]. Other relevant studies include [11-15].

For disaster preparedness with respect risk-based water management, there is need for the comprehension of historical variation in extreme rainfall and any associated drivers. Some of the recent rainfall-related disasters which claimed lives and property in the study area include the flooding in Kasese region of Uganda in the early May 2013 and midMay 2016 as well as the deadly landslides in the Mount Elgon which occurred in March 2010 and June 2012. Generally, some of the hotspots for the recent flooding events include Kasese district as well as the Teso region (covering districts of Amuria, Katakwi, Soroti, Kumi, Bukedea, and Kaberamaido). Nonetheless, the flooding occurrences of September 2007 were widespread and caused havoc in the eastern, western, and the central parts of Uganda. The landslides in Uganda especially in the western part are due to seismicity but not rainfall [16]. On the other hand, the landslides in the foot of the Mount Elgon at the Uganda-Kenya boarder are rather due to the high rainfall than the seismicity [17].

It is possible that the occurrences of rainfall-related disasters in the study area may also be exacerbated by the alteration of catchment behavior due to anthropogenic factors such as deforestation, overgrazing, and expansion of urbanized areas. Whereas plans can be put in place to deal with the influence from the anthropogenic factors, for example, by water catchment restoration, local community sensitization, and regulation of the management strategies for river banks, mountainous areas, and so forth, comprehension of the spatiotemporal variation in the rainfall 


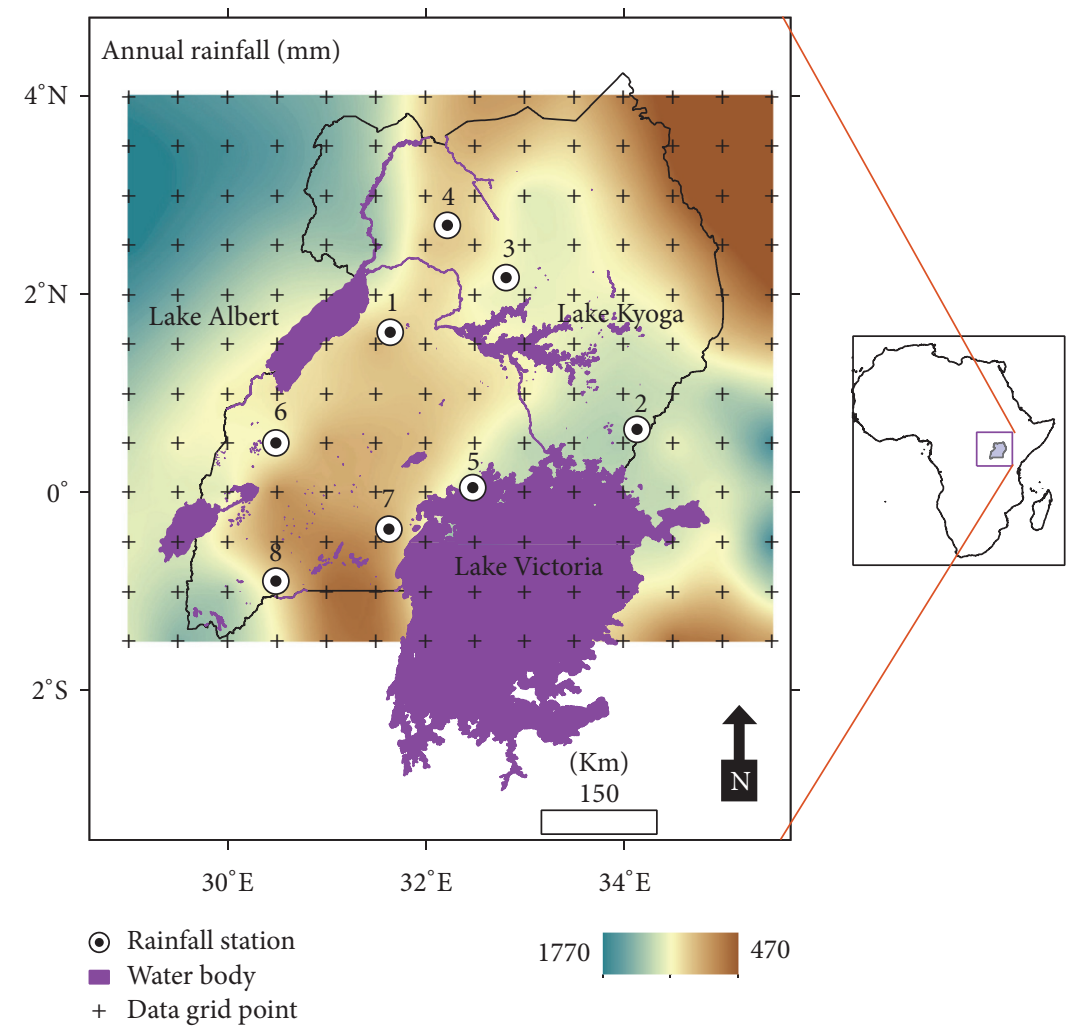

FIGURE 1: The study area showing the spatial domain of the rainfall data and locations of some selected meteorological stations (see Table 1 for details). The background map is the annual rainfall total ( $\mathrm{mm}$ ) obtained by surface interpolation (kriging method) based on data from 1948-2008.

extremes would offer a valuable support for the risk-based planning and management of the applications related to such rainfall-based disasters. Unfortunately, the poor distribution of meteorological stations, short-term data record length, and questionable data quality altogether affect the analyses which would offer an in-depth understanding based on the clarity of the spatiotemporal rainfall variability and trends in Uganda. Furthermore, previous studies on rainfall variability $[18,19]$ and trends [20-25] over the region where the study area is located tended to focus mainly on seasonal or annual totals. Such analyses of seasonal or annual rainfall totals are relevant for rather agricultural practices than risk-based water resources management. However, the trends and variability of the annual rainfall maxima were recently conducted by [26] though based on a limited coverage of only the Lake Victoria Basin. Eventually, the evidence of detailed studies which analyzed trends and variability of extreme rainfall events by considering the entire Uganda could not be found in literature by the time of this study.

Therefore, this study is aimed at (1) investigating the geospatial trends and variability in extreme rainfall intensities and (2) assessing the possible drivers of the rainfall variability.

\section{Materials and Methods}

2.1. Study Area. Uganda (Figure 1) is a land-locked country located at the heart of the sub-Saharan Africa. The country has tropical climate and is semiarid in the northeast. Uganda covers about $241,040 \mathrm{~km}^{2}$ of which nearly $18.2 \%$ comprises water bodies and swamps. Some of the topographical features which may influence rainfall variation in the study area include mountains (i.e., Mount Elgon and Mount Rwenzori) and water bodies (e.g., Lake Albert, Lake George, Lake Edward, Lake Victoria, Lake Kyoga, and the White Nile River). Uganda has the Western Rift, also called the Albertine Rift, along its western border. The population density of the various districts of Uganda by 2010 is provided in Figure 2.

2.2. Rainfall Data. In gridded $\left(0.5^{\circ} \times 0.5^{\circ}\right)$ form, global daily rainfall data of the Princeton Global Forcings (PGFs) [27] were downloaded from http://hydrology.princeton.edu/data/ pgf/0.5deg/ [accessed on 12-02-2016]. The spatial domain over which the PGF rainfall was extracted had a total of 168 grid points (see Figure 1 for the grid points). Due to their robustness for variability analyses, PGF-based data have been used in a number of studies [28, 29]. The PGF-based series which were of $1^{\circ} \times 1^{\circ}$ spatial resolution and initially covered the period $1948-2006$ were recently refined to $0.5^{\circ} \times 0.5^{\circ}$ grid cell size and extended from 1948 to 2008. The PGFs are observational-reanalysis hybrid [27]. In other words, the data are derived from a combination of the NCEP-NCAR reanalysis dataset [30] with several other observational-based rainfall products including the TRMM, the CRU TS2.0, the GPCP, and the NASA Langley Research Center SRB. The PGF 


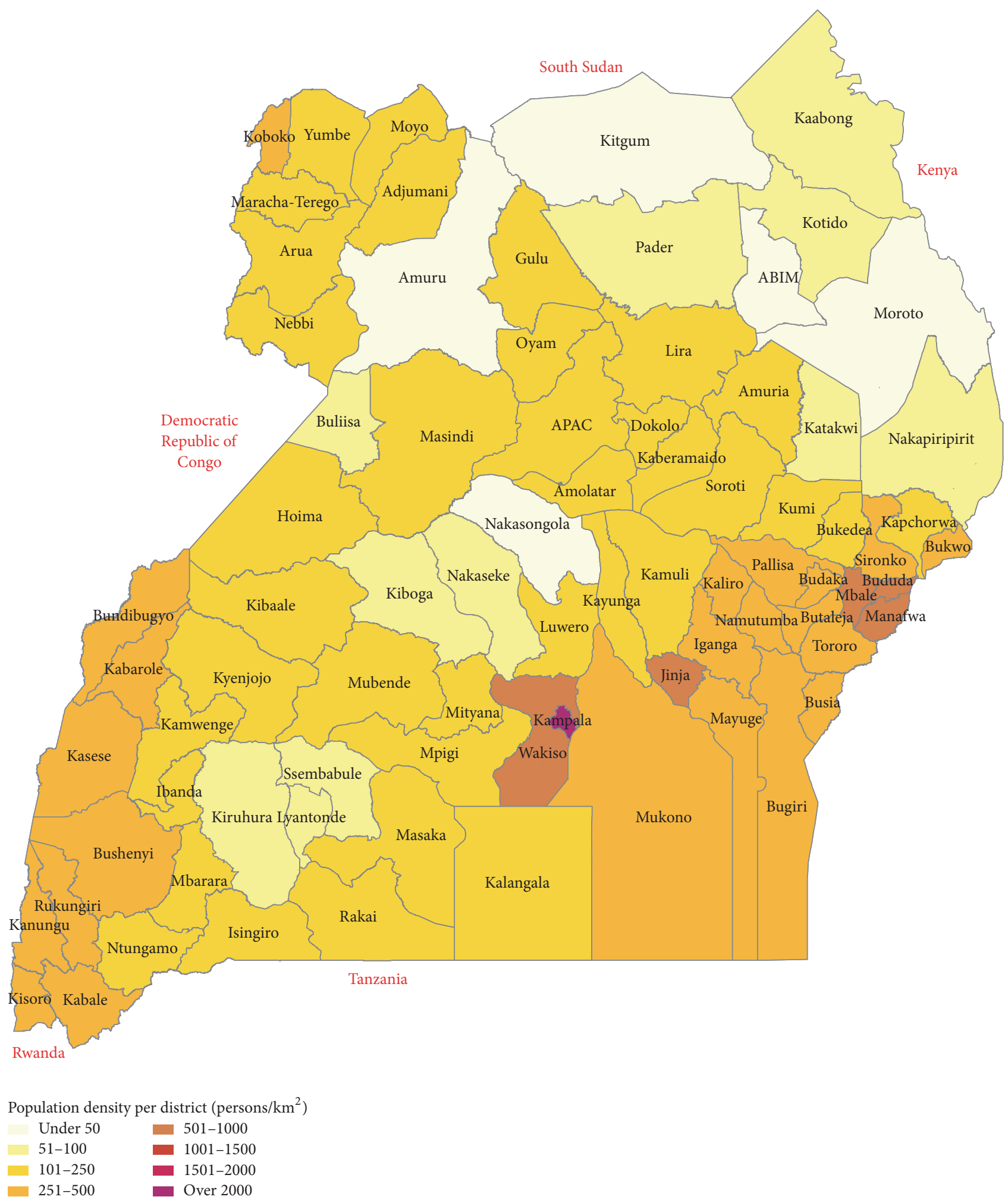

FIgURE 2: The population density of the various districts of Uganda by 2010 (source: Uganda Water Supply Atlas 2010, Ministry of Water and Environment, Uganda). 
TABLE 1: Correlation between PGF-based series and observed rainfall at selected stations.

\begin{tabular}{|c|c|c|c|c|c|c|c|}
\hline \multirow{2}{*}{ S. number } & \multirow{2}{*}{ Station name } & \multicolumn{2}{|c|}{ Coordinate } & \multicolumn{2}{|c|}{ Data record period } & \multicolumn{2}{|c|}{ Correlation } \\
\hline & & Long. & Lat. & From & To & Coefficient & Crit. \\
\hline 1 & Masindi & 31.71 & 1.68 & 1965 & 1997 & 0.26 & 0.34 \\
\hline 2 & Tororo & 34.18 & 0.68 & 1965 & 1997 & -0.15 & 0.34 \\
\hline 3 & Lira & 32.89 & 2.25 & 1965 & 1997 & -0.33 & 0.34 \\
\hline 4 & Gulu & 32.28 & 2.77 & 1965 & 1997 & 0.49 & 0.34 \\
\hline 5 & Entebbe & 32.46 & 0.05 & 1955 & 1996 & 0.52 & 0.30 \\
\hline 6 & Mbarara Met. & 30.60 & 0.56 & 1950 & 2004 & 0.36 & 0.26 \\
\hline 7 & Kamenyamigo & 31.67 & -0.30 & 1965 & 1986 & 0.60 & 0.39 \\
\hline 8 & Rwoho Forest & 30.55 & -0.85 & 1965 & 1986 & 0.43 & 0.39 \\
\hline
\end{tabular}

Crit.: correlation critical value at the significance level of $5 \%$.

Bold values denote that $H_{0}$ (no correlation) was rejected at the significance level of $5 \%$.

data had no missing values over the entire data period at all the selected grid points.

Generally, reanalyses/model rainfall datasets are known to be biased in reproducing observed extreme events [31], though some freely available products (e.g., PERSIANNCDR) are starting to become promising in the representation of extreme hydrometeorological conditions over certain regions of the world [32]. In this study, daily data at eight meteorological stations (Table 1) across the study area were used to first investigate the validity of the PGF series for variability analyses. Data from the selected stations 1-5 were obtained from the Ministry of Water and Environment, Uganda. Quality-controlled data for station 6 was adopted from [33]. Furthermore, series for stations 7 and 8 were obtained from a study by [34]. Some missing values in the data at stations 1-5 were infilled using the inverse distance weighted interpolation technique as similarly applied by [34].

At the location of each station, extreme rainfall events were extracted from both observed and PGF series. One way to obtain extreme events from daily rainfall is to extract the highest intensity in each year. To even out the possible overestimation and/or underestimation of extreme events by the PGF data, average of fifteen highest values in each year was deemed representative of the general condition of extreme rainfall and used for the statistical analyses. Furthermore, for consistency of the validity check with respect to the target of this study, nonparametric anomaly indicator method (NAIM) was applied to extract decadal anomalies from observed and PGF rainfall series. The attractive feature of NAIM is its capacity to eliminate the influence of possible outliers in the series on variability analysis. The cooccurrence of the extracted anomalies from both the observed and PGF-based rainfall is shown graphically (Figure 3) and statistically (Table 1). It is noticeable from Figure 3 that the oscillation highs and lows from the observed decadal anomalies are somewhat overestimated/underestimated by the PGF series. Statistically, the null hypothesis $H_{0}$ (there is no correlation between the anomalies from observed rainfall and PGF series) was tested at the significance level of $5 \%$. Whereas $H_{0}$ was rejected at stations $4-8, H_{0}$ was accepted at stations 1-3 (Table 1). Furthermore, at stations 2-3, negative correlation was obtained, meaning that when the observed rainfall exhibits an increase over some data period, the PGF series correspondingly reproduces a decrease. These results from Figure 3 and Table 1 indicate that the performance of PGF series in reproducing the variability in observed rainfall varies from one location to another. This could be due to the limitation of the PGF to adequately capture the influence from regional features, such as topography and water bodies, on the spatial variation in the extreme rainfall statistics across the study. However, the use of PGF series for analyses of variability especially after some filtering of the fluctuations in the data using suitable temporal scale through NAIM as applied in this study can still give an insight about the changes in the extreme rainfall across the study.

2.3. Climate Indices. For rainfall variability attribution, three climate indices were obtained. These series which were all of monthly temporal resolution included the Indian Ocean Dipole (IOD), the North Atlantic Oscillation (NAO) index [35], and Niño $3[36,37]$. The IOD is the anomalous sea surface temperature (SST) difference between the western $\left(50^{\circ}-70^{\circ} \mathrm{E}\right.$ and $\left.10^{\circ} \mathrm{S}-10^{\circ} \mathrm{N}\right)$ and south-eastern $\left(90^{\circ}-110^{\circ} \mathrm{E}\right.$ and $\left.10^{\circ} \mathrm{S}-0^{\circ} \mathrm{N}\right)$ equatorial Indian Ocean. The NAO index is the normalized sea level pressure (SLP) difference between Reykjavik, Gibraltar, and Azores [35]. Niño 3 is the area averaged Niño SST indices for the tropical Pacific regions $90-150^{\circ} \mathrm{W}$ and $5^{\circ} \mathrm{N}-5^{\circ} \mathrm{S}$. These climate indices were selected based on their relevance demonstrated in past studies [18, 19, 26, 38] to explain the variation in rainfall of the equatorial region where the study area is located. The climate indices were downloaded from the following links:

(a) http://www.jamstec.go.jp/frcgc/research/d1/iod [accessed 20-01-2014] for the IOD

(b) http://www.esrl.noaa.gov/psd/gcos_wgsp/Timeseries/NAO/ [accessed 16-04-2016] for NAO

(c) http://www.esrl.noaa.gov/psd/gcos_wgsp/Timeseries/Nino3/ [accessed 29-01-2013] for Niño 3

For trends and variability analyses, monthly series of the climate indices were converted to annual time scale as that for the gridded rainfall. 


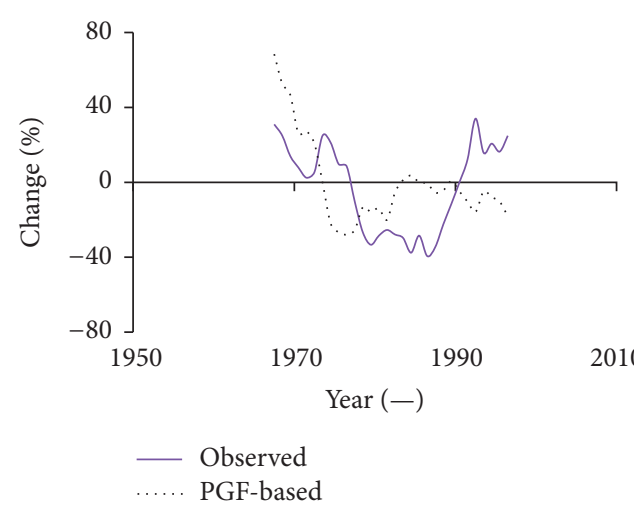

(a)

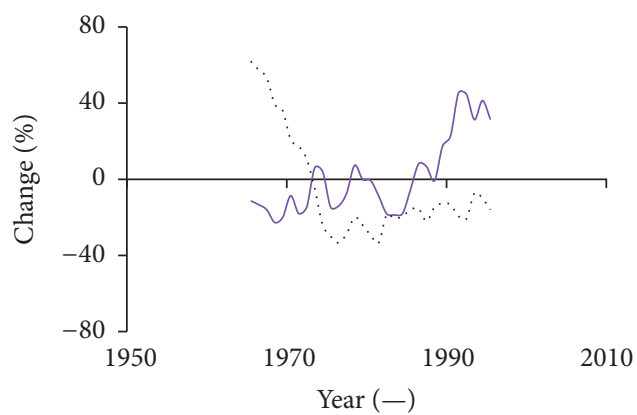

- Observed

..... PGF-based

(c)

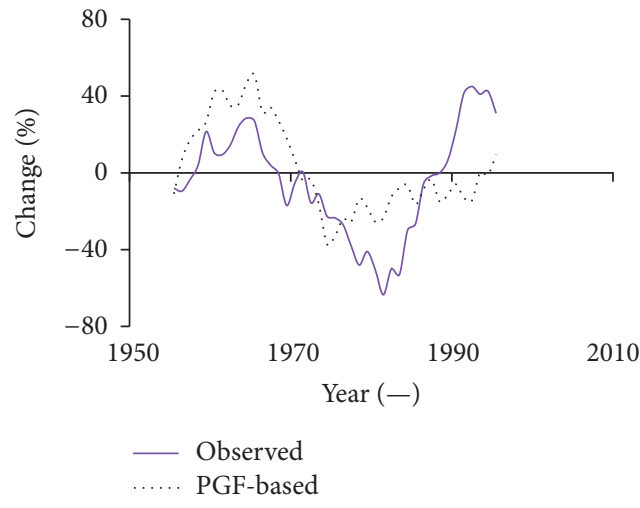

(e)

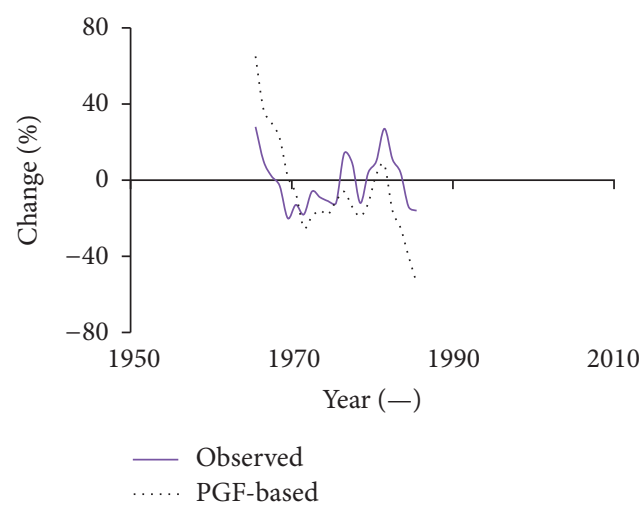

(g)

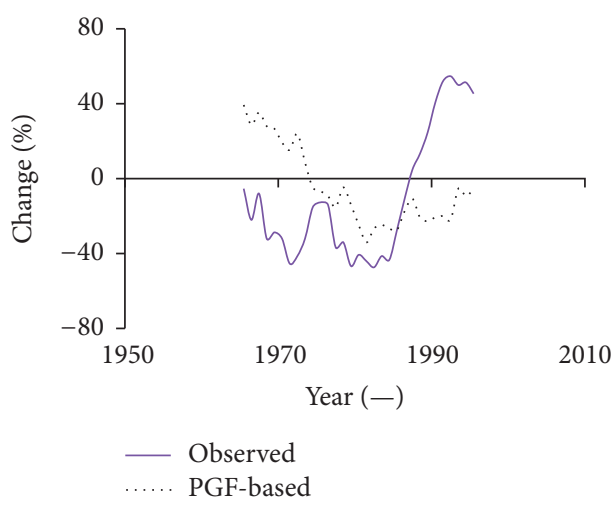

(b)

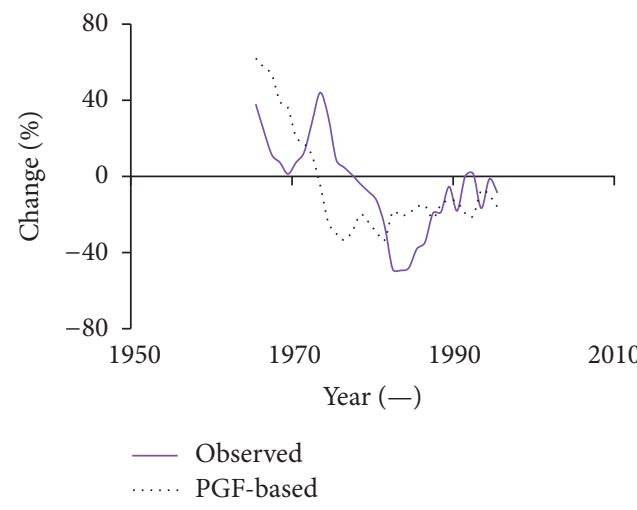

(d)

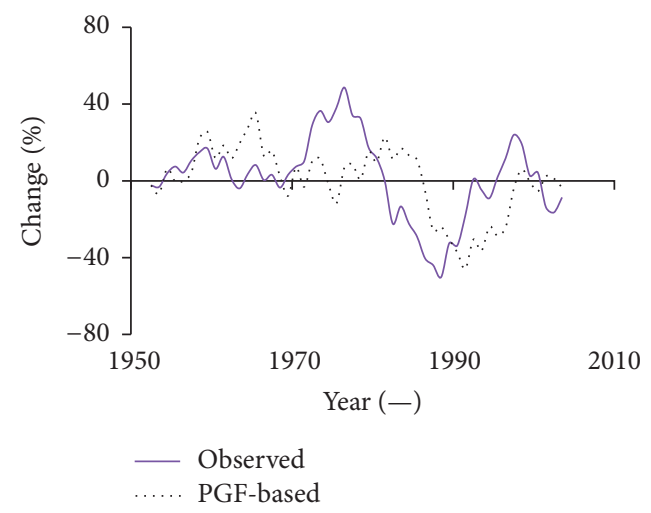

(f)

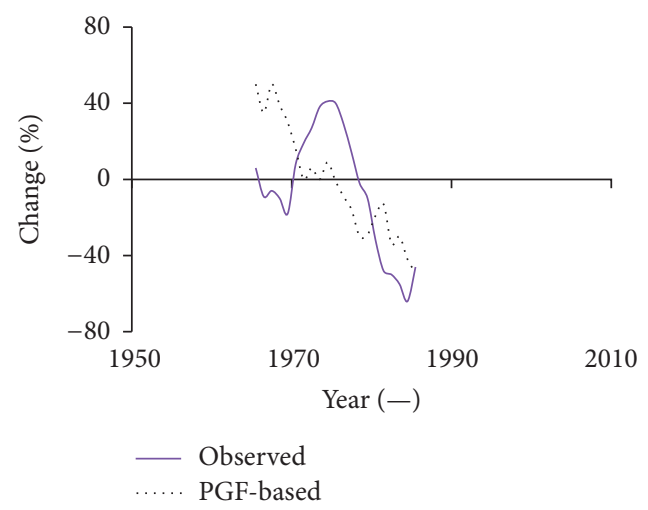

(h)

FIGURE 3: NAIM decadal changes (\%) in the top fifteen rainfall events in each year based on observed and PGF-based series at stations (a) 1, (b) 2, (c) 3, (d) 4, (e) 5, (f) 6, (g) 7, and (h) 8. 


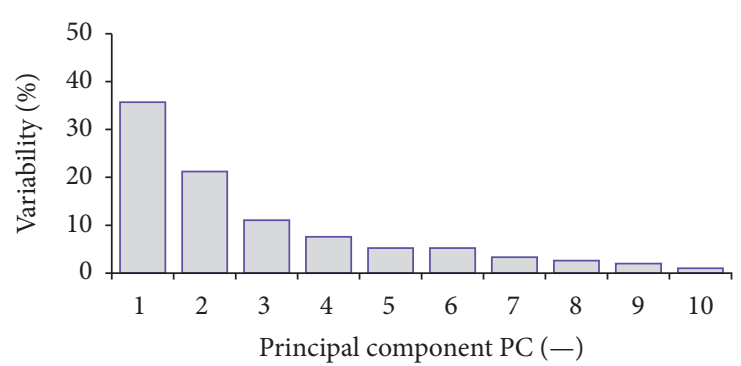

(a)

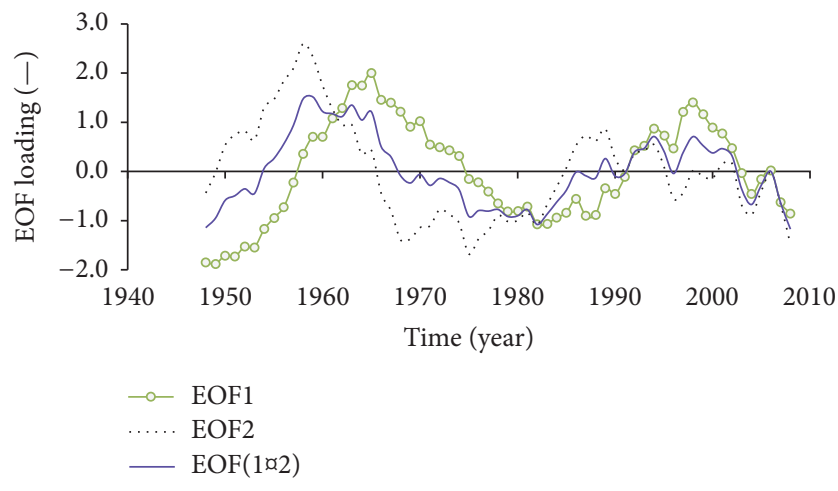

(b)

FIGURE 4: (a) Percentage of variability explained in the rainfall and (b) the first (EOF1) and second (EOF2) dominant EOF factor loadings. $\mathrm{EOF}(1 \mathrm{a} 2)$ denotes the average of EOF1 and EOF2.

\subsection{Rainfall Variability Analyses}

2.4.1. Nonparametric Anomaly Indicator Method (NAIM). Anomalies characterizing variability in the series were derived using the NAIM [39-41]. The NAIM which relies on convolution of rescaled series was applied to (1) the rainfall at each grid point and (2) the selected climate indices and/or series. To implement the NAIM in this study, freely available trend and variability analyses tool "CRD-NAIM" $[42,43]$ and its supporting documents were downloaded from https://sites.google.com/site/conyutha/tools-to-download/ [accessed on 09-07-2016]. Some further information on the method is provided in Appendix A.

2.4.2. Empirical Orthogonal Function (EOF). To examine the structures which explain the maximum amount of variance in the NAIM anomalies at the various grid points, the EOF analysis was conducted. The structure and sampling dimensions were taken in terms of space and time, respectively. The EOF was obtained as a set of structures produced in the first (i.e., the structure) dimension. The complementary set of structures referred to as the Principal Components (PCs) was produced in the sampling (i.e., time) dimension. Of course, the EOFs and PCs are orthogonal in their own dimension. What makes the PCs so valuable in variability analyses is the orthogonality property, that is, lack of correlation in time. To isolate regions with similar temporal variation so as to enable the identification of areas with maximum correlation between the variables and their components, rotation of the eigenvectors was required $[44,45]$. This was implemented using the Varimax procedure, the details on which can be found well documented in several literature sources $[44,46]$.

2.4.3. Correlation Analyses. Under the null hypothesis $H_{0}$ of no correlation between the rainfall variability and the variation in the possible driver, the cooccurrence of the NAIM anomalies from the climate indices and those of rainfall at each grid point was assessed at the significance level $\alpha=5 \% . H_{0}$ was accepted if the coefficient of the correlation was less than the critical value.

\subsection{Trend Analyses}

2.5.1. Statistical Trend Test. To test null hypothesis $H_{0}$ of no trend in terms of the significance of the nonzero slope of a linear variation of the series (at each grid point) with time, the method of [41-43] which is based on the cumulative rank difference was used. This recently developed trend testing methodology is also incorporated in the tool "CRD-NAIM" mentioned in Section 2.4.1. The detail of the statistical CRD test is provided in Appendix B.

2.5.2. Trend Slope. Whereas the statistic CRD test gives information about the direction of the increase or decrease in the variable, the magnitude of the change is given in terms of the trend slope $m$. The value of $m$ was computed at each rainfall grid point by the approach of $[47,48]$.

\section{Results and Discussion}

\subsection{Rainfall Variability Analyses}

3.1.1. Temporal Variability. Figure 4 shows the temporal loadings as well as the variation in the amount of explained variability with the PCs. For the first and second PCs (Figure 4(a)), 35.7\% and 21.2\%, respectively, of the variability were explained. Considering the CPC Merged Analysis of Precipitation (CMAP) for the period 1979-2001 over East Africa where Uganda is located [25] also found the first (EOF1) and second (EOF2) dominant modes of variability to explain about $30 \%$ and $15 \%$, respectively. According to [49], to obtain a distinctly separated EOF from a sample of size $n$, the sampling error $\delta \lambda=\lambda(2 / n)^{0.5}$ must be smaller than its spacing from the neighboring eigenvalues. Eventually, focus was given to the first two EOFs because they fulfill the criterion of [49]. In other words, the first two EOFs were deemed more meaningful in explaining the variability than the remaining EOFs which probably represent noise.

In the temporal EOF factor loadings, the zero horizontal line, that is, the reference for the variability corresponds to the mean of the long-term series. Considering the entire spatial 


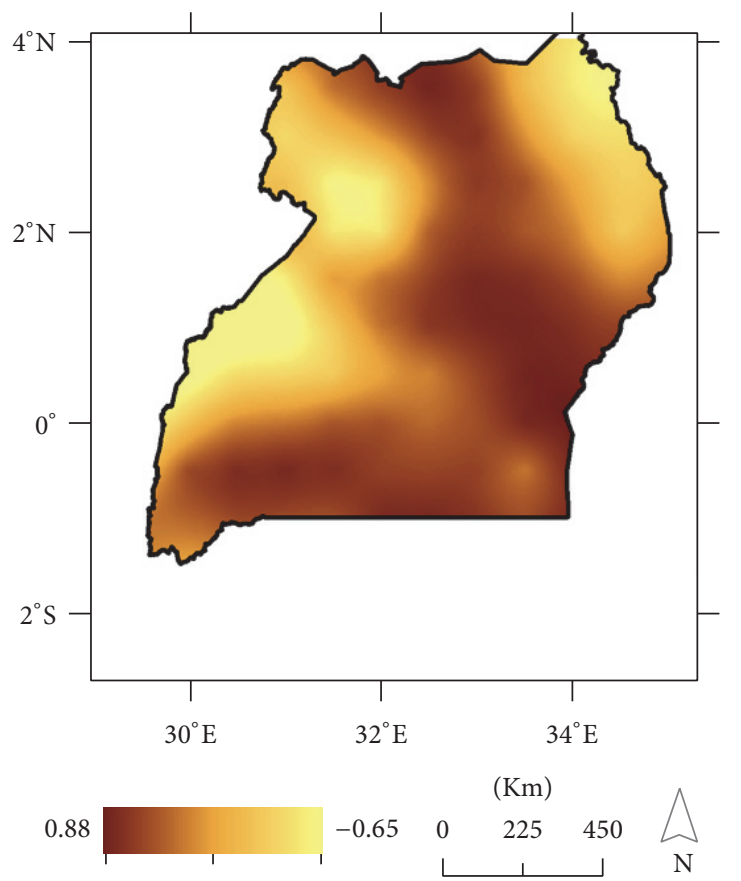

(a)

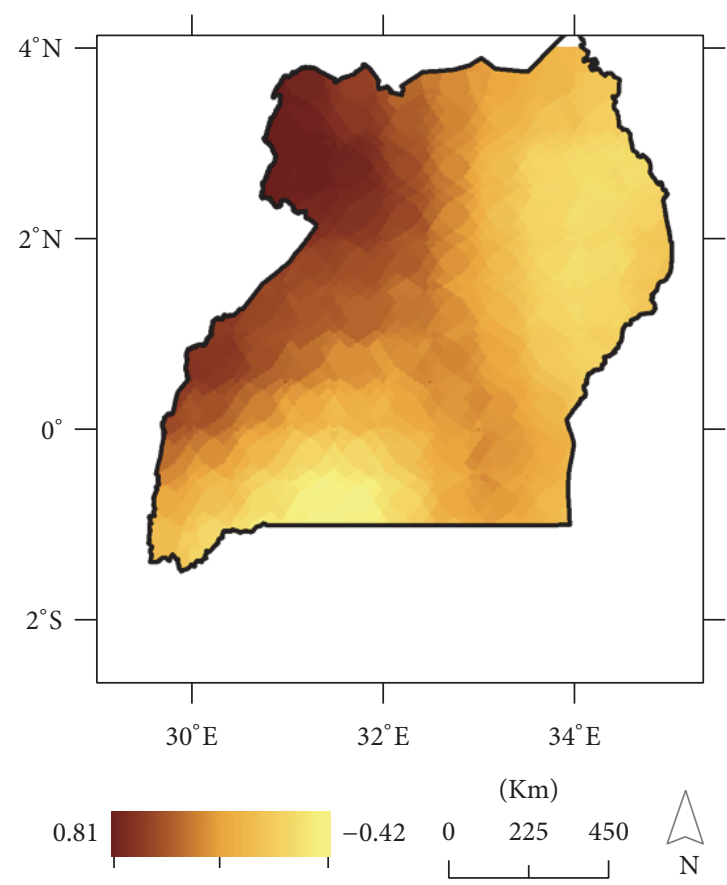

(b)

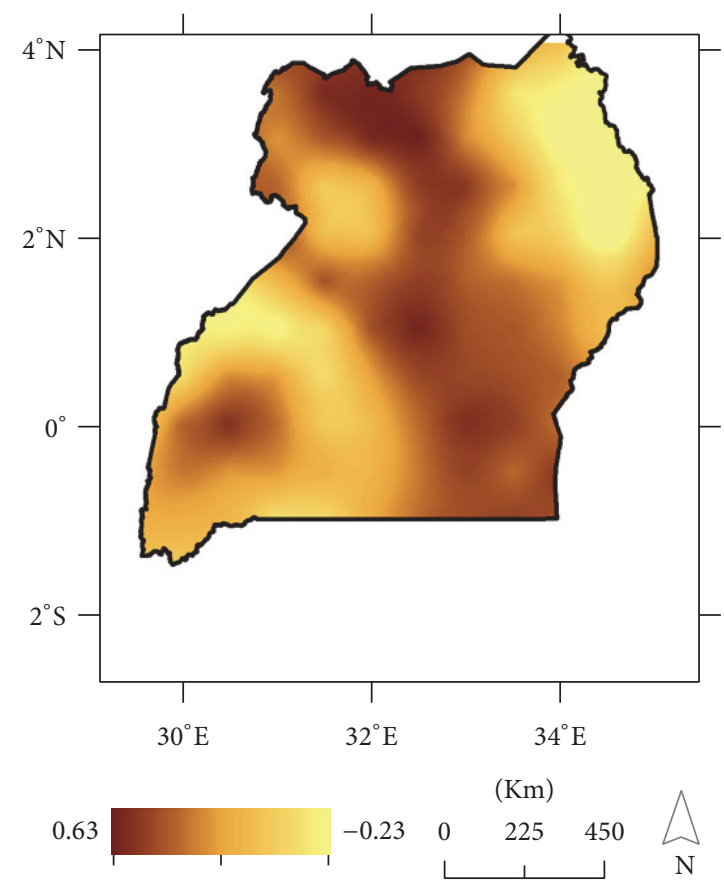

(c)

FIGURE 5: Spatial variation in (a) EOF1, (b) EOF2, and (c) EOF(1a2) sets of EOF factor loadings obtained by surface interpolation (Kriging method).

domain where Uganda is located, the mean of the first two dominant modes of variability, $\operatorname{EOF}(1 \propto 2)$, shows that there was an oscillation high $(\mathrm{OH})$ of the loadings from the mid1950 s to the late 1960s and again in the 1990s as well as the early 2000s (Figure 4(b)). From around 1970 to the late 1980s, the loadings exhibited an oscillation low (OL).
3.1.2. Spatial Variability. Figure 5 shows the spatial variation of the EOF factor loadings. For the most dominant mode of variability, EOF1 (Figure 5(a)), areas around Lake Victoria, the south-western section, and the northern region in the districts of Lira, Pader, and Kitgum tended to load positively. However, western areas around Lake Albert 


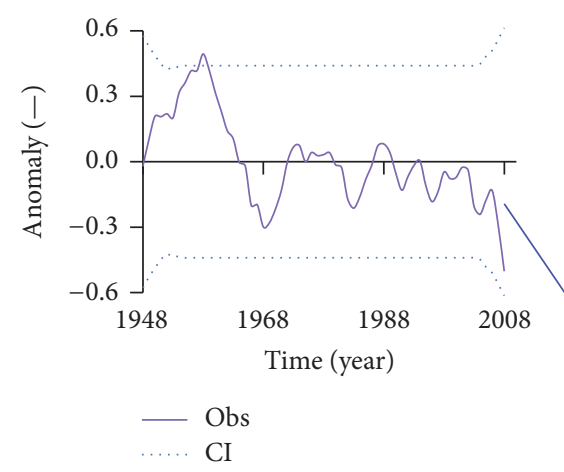

(a)

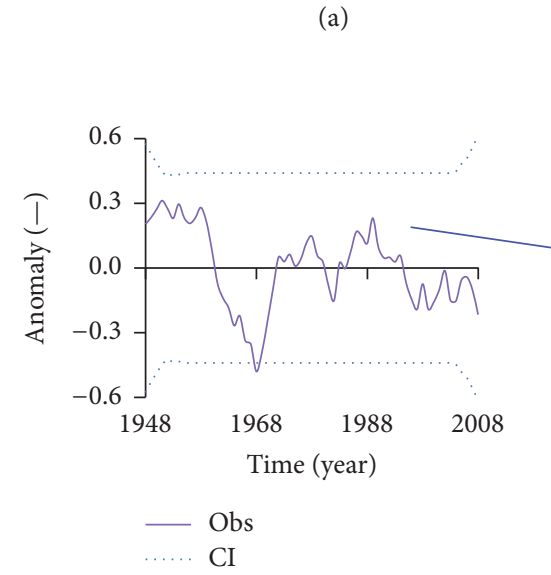

(b)

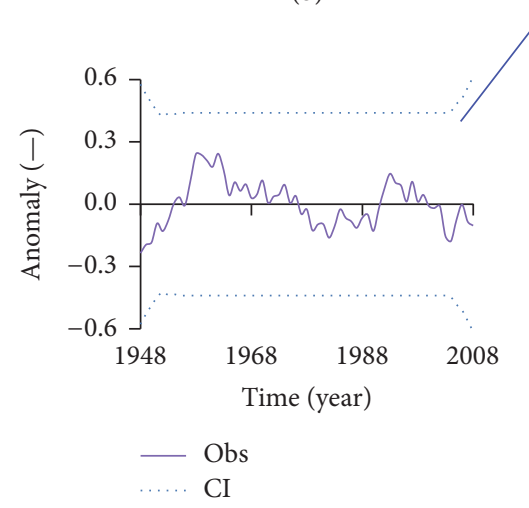

(c)
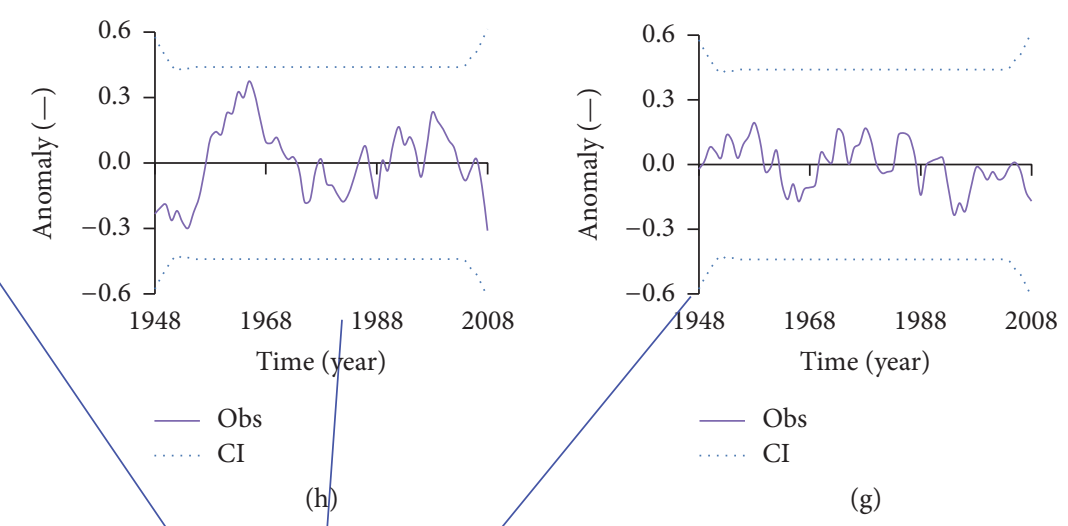

(g)
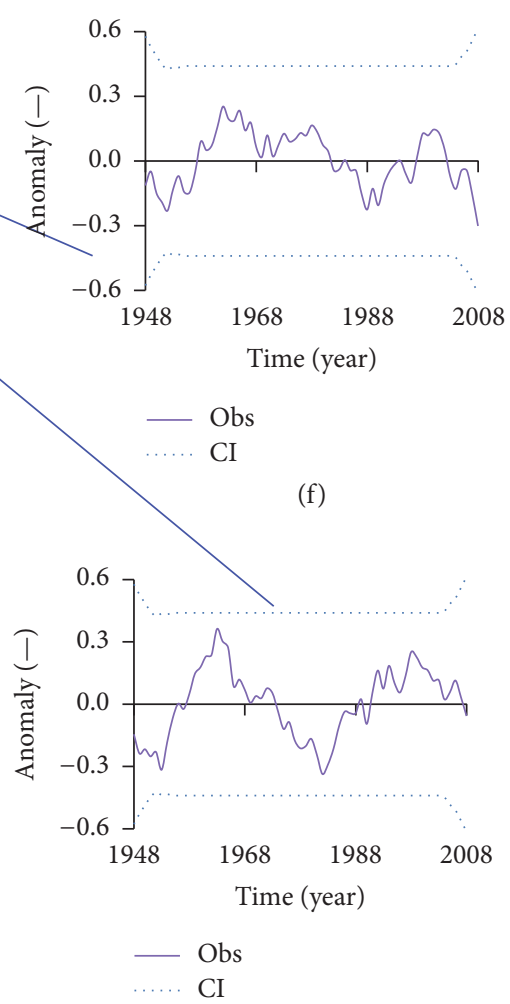

(e)

FIGURE 6: Observed changes (Obs) in the rainfall from (a) to (h) different parts of Uganda based on the spatial variation in the sites for the EOF factor loadings.

and the north-eastern region loaded negatively. For the second dominant mode of variability, EOF2 (Figure 5(b)), the western half of the area north of equator generally loaded positively; the eastern half had negative loadings. The average of the spatial patterns of EOF1 and EOF2 is presented in $\operatorname{EOF}(1 \times 2)$ (Figure 5(c)). The rainfall anomalies loaded negatively in the north-eastern region. The spatial differences in the EOF factor loadings indicate how the influence from the large-scale Ocean-Atmosphere interactions on the rainfall variability may vary in strength from one part of the country to another. For instance, the migration of the Intertropical Convergence Zone (ITCZ) leads to latitudinal difference in the rainfall. Furthermore, the influence from the difference in the microclimate can also lead to the spatial variation of rainfall across the country. Other factors which could lead to heterogeneity in rainfall across the study area include the influences from regional features, for example, topography and water bodies as already highlighted in Section 1, and so forth.

Figure 6 shows the differences in the spatiotemporal variation in the rainfall decadal anomalies. In the northwestern region (Figure 6(a)) as well as areas south of the Lake Albert (Figure 6(b)), the rainfall was above reference in the 1950s up to mid-1960s. From the late 1960s till the end of the data period (2008), rainfall was characterized more by decrease than increase. In the south-western area 


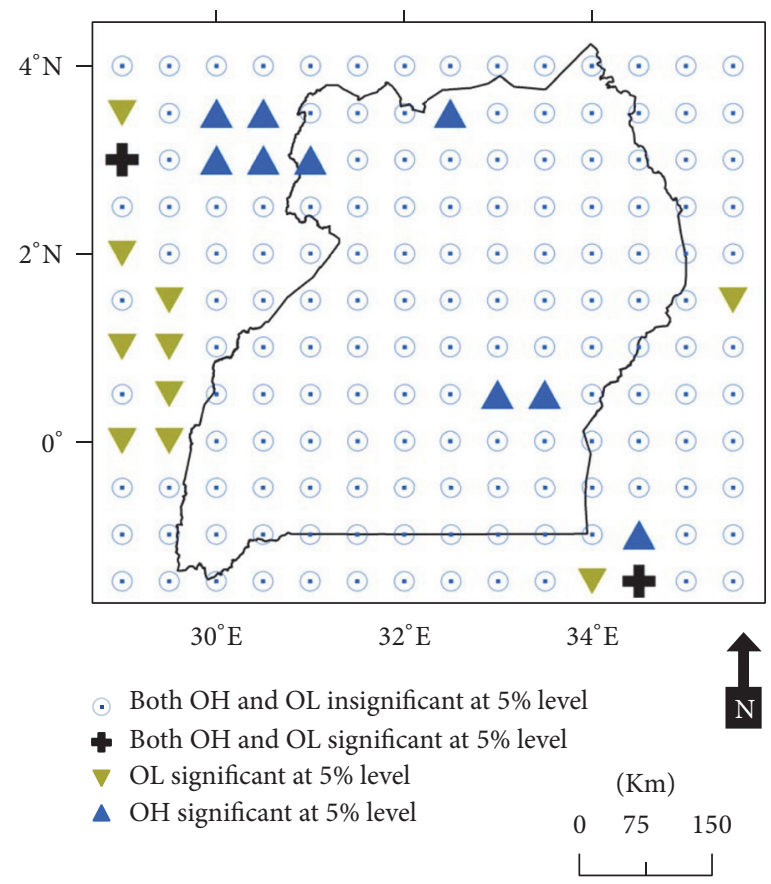

FiguRE 7: Spatial differences in the significance of rainfall variability.

near the border with Rwanda, the $\mathrm{OH}$ and $\mathrm{OL}$ were in the 1960s and 1980s, respectively (Figure 6(c)). However, in the south-eastern region (Figures 6(d) and 6(e)), the $\mathrm{OH}$ was in the 1960s and 1990s. The OL was in the early 1950s and the 1970s. These results are consistent with the findings from a recent study [26] on the variability of annual maxima of observed or station-based rainfall over the same location. For the Teso region as well as the areas around the Mount Elgon (Figure 6(f)), the OL was in the early 1950s as well as around the 1990s. The OH occurred in the 1960s and 1970s. For the northern part (Figure 6(h)) where Pader and Kitgum districts are located, the OL and OH were in the 1950s and 1960s, respectively. The rainfall anomalies from the 1970 s to late 2000 s tended to fluctuate about the reference. In the northeastern region (Figure 6(g)) of Kaabong, Kotido, and Moroto districts, the rainfall anomalies crossed the reference several times over the data period. In other words, the variability in the rainfall was not in a persistent manner.

It is noticeable that the rainfall variability tended to differ (though to varying extents) from one part of the country to another. As briefly mentioned before, this could be probably due to the dissimilarity in the microclimate or the influence from regional features such as water bodies, topography, or transition in land cover and/or use on the rainfall variation.

The null hypothesis $H_{0}$ (natural randomness) is rejected (accepted) if some NAIM anomalies fall outside (inside) the $(100-\alpha \%)$ confidence interval. Although the averaged NAIM anomalies for the various regions as shown in Figure 6 were not generally statistically significant at 5\% level, the significance of the temporal variability at the individual grid points is presented in Figure 7.
3.1.3. Linkage of Rainfall Variability to Large-Scale OceanAtmosphere Interactions. Figure 8 shows the linkage of the rainfall variability to the variation in the climate indices. The spatial map was obtained by surface interpolation (kriging method). The most dominant mode of variability (EOF1) (Figure 5(a)) resonates well with the variation of the IOD (Figure 8(a)) especially in the southern part, that is, areas in and around the Lake Victoria. On a yearly basis, the latitudinal movement of the ITCZ brings about differences in the rainfall in the southern and northern parts of Uganda. As the ITCZ gradually leaves the equator and moves northwards, the summer rains steadily increase in magnitude, thereby transforming the bimodal rainfall pattern which is typical of the areas within and around the Lake Victoria Basin to a unimodal type in the northern part. This ITCZ migration is linked to the variation in the SST from the Indian Ocean, thereby explaining why the most dominant spatial structure, that is, EOF1 (Figure 5(a)), is comparable to the correlation between the rainfall variability and the anomalies in IOD (Figure 8(a)).

The rainfall variability in the northern part seems to be more linked with the variation in the Niño 3 than that of the IOD. Although the strength of the linkage between rainfall and Niño 3 is lower than that with IOD, the correlation between the rainfall temporal anomalies and the variation in the Niño 3 is also visible in the south-western region. In a previous study on the El-Niño Southern Oscillation (ENSO) and interannual rainfall variability in Uganda [19], both negative and positive correlation coefficients were also found with Niño 3. Generally, the linkage of the rainfall variability in the equatorial region with the ENSO is also well documented [18, 25, 50]. 


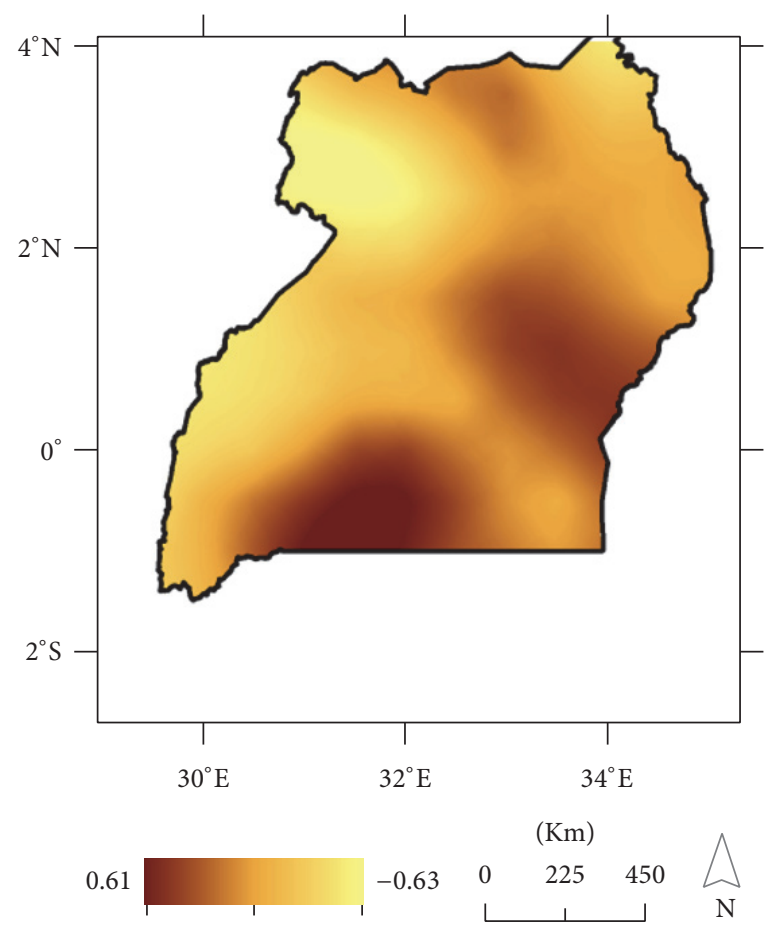

(a)

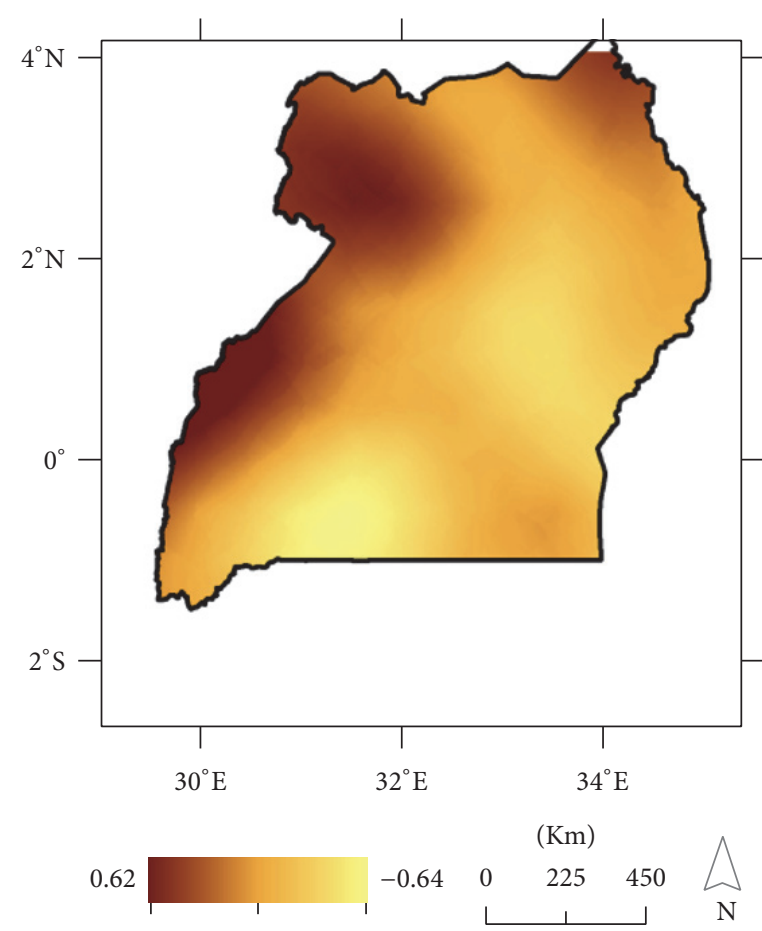

(b)

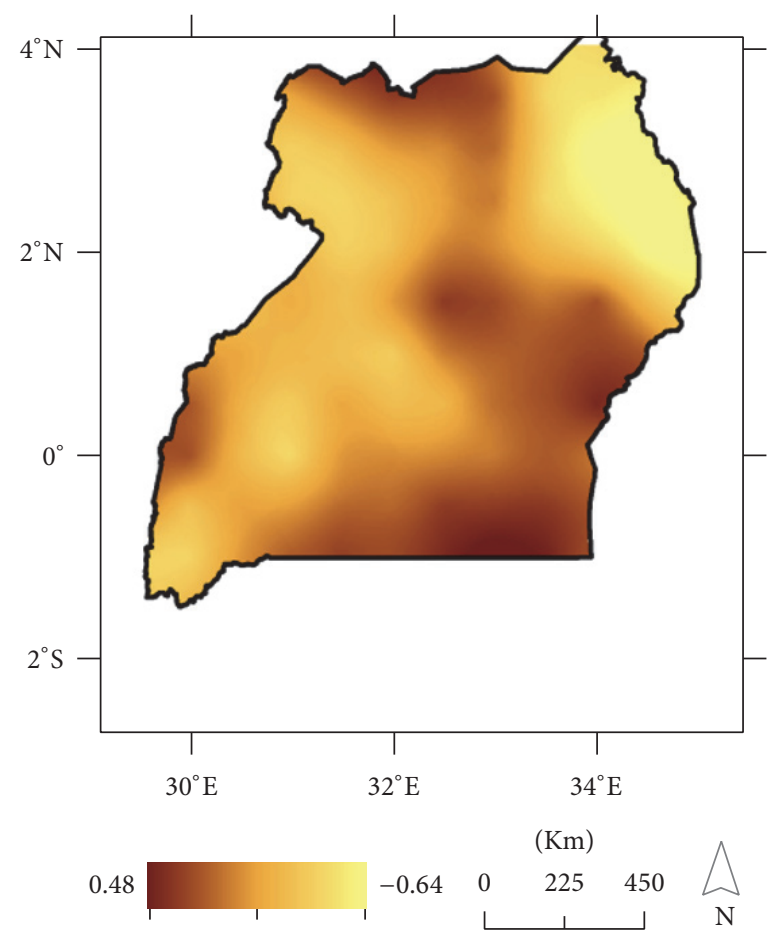

(c)

FIgURE 8: Correlation between NAIM anomalies from rainfall and those of (a) IOD, (b) NAO, and (c) Niño 3.

The second dominant mode of variability (EOF2) (Figure 5(b)) corresponds to the variation of the NAO index (Figure 8(b)). This suggests that the rainfall in the western half of the area above the equator is influenced by the oscillation from the North Atlantic Ocean.
3.2. Statistical Trend Analyses. Figure 9 shows statistical trend results in the extreme rainfall intensities in each year. The spatial map (Figure 9(a)) was obtained by surface interpolation (Kriging method). Based on Figure 9(a), whereas the southern part (especially around Lake Victoria) as well as 


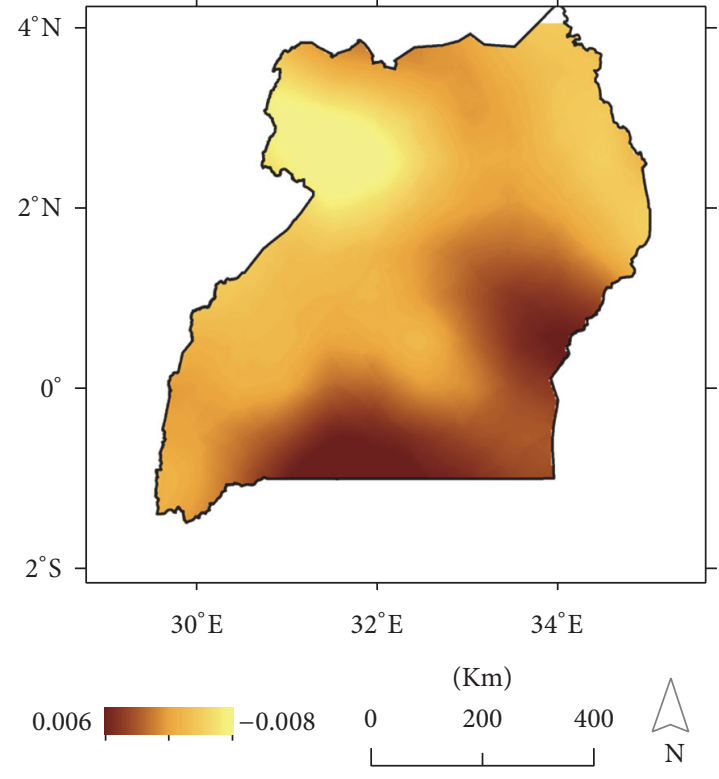

(a)

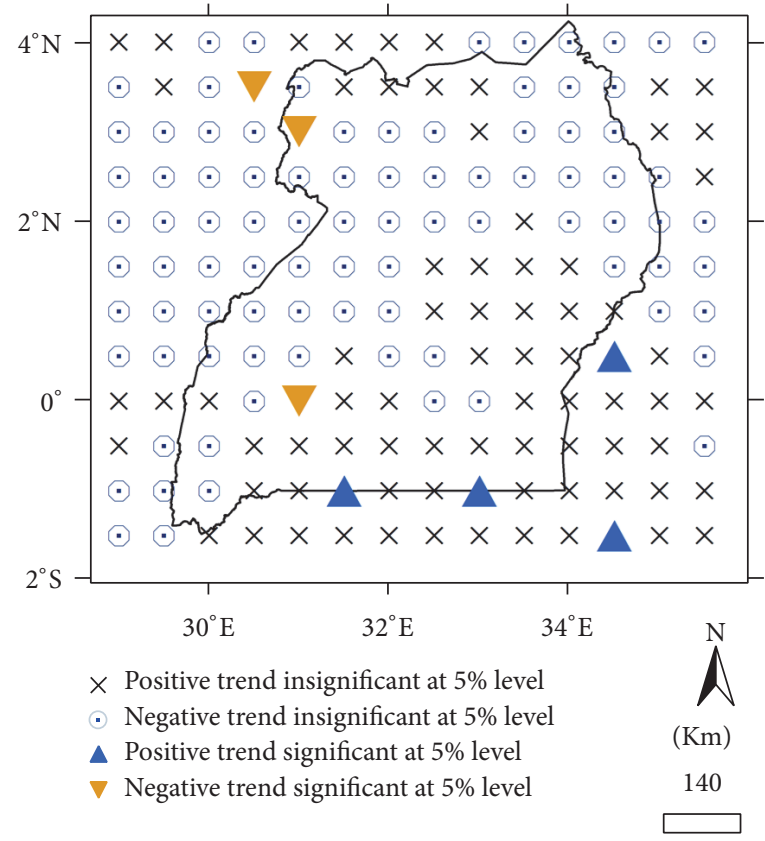

(b)

FIgURE 9: Trends in terms of (a) slope $m$ (mm/day/year) and (b) direction.

the south-western districts of Tororo, Bududa, and so forth had a long-term increase in the rainfall, the northern region was characterized by a decrease. It might be possible that the recent landslides in Bududa in March 2010 and June 2012 could be due to the recent increase in rainfall. The West Nile districts of Zombo, Nebbi, and Arua to some extent had notable decrease in rainfall. For the south-western Uganda, the rainfall extreme events were characterized by both decrease and increase. Similar result was also found by [51] though using seasonal and annual rainfall totals. The locations with significant trend directions are shown in Figure 9(b).

\section{Conclusions}

This study assessed the spatiotemporal variability and trends in extreme rainfall intensities based on high-resolution $\left(0.5^{\circ} \times 0.5^{\circ}\right)$ gridded daily series of the Princeton Global Forcings (PGFs) covering the entire Uganda in East Africa for the period 1948-2008. The variability analyses were based on the empirical orthogonal function and nonparametric anomaly indicator method. The cooccurrence of the rainfall variability with the large-scale Ocean-Atmosphere interactions was investigated. Statistical analyses of trends were conducted using the recently introduced method which relies on the cumulative rank difference in the data.

Generally, rainfall was above the long-term mean from the mid-1950s to the late 1960s and again in the 1990s as well as the early 2000s. However, from around 1970 to the late 1980s, rainfall was characterized by a decrease. The most dominant mode of variability (EOF1) resonates well with variation in the sea surface temperature of the Indian Ocean. The second dominant mode of variability (EOF2) corresponds to the variation of the sea level pressure in the North Atlantic Ocean. The influence of Niño 3 on the rainfall variability of some parts of the country was also evident.

Whereas generally the southern part (especially around Lake Victoria) as well as the south-western districts of Tororo, Bududa, and so forth had a long-term increase in the rainfall, the northern region was characterized by a decrease in rainfall. For the data extracted at a total of 168 grid points, the null hypothesis $H_{0}$ (no trend) was rejected for 7 datasets. For positive and negative trends, $H_{0}$ was rejected at 4 and 3 grid points, respectively.

Based on the rainfall changes assessed using the PGF data, the temporal rainfall variation over the data period was characterized by both oscillatory and long-term increase or decrease. It is known that when short-term data are used to conduct frequency analyses, the derived rainfall quantiles might be biased from those that would be obtained from long-term series. Given that the variation in rainfall may be explained by the anomalies in suitable climate indices, such biases in the rainfall quantiles for short-term data can be estimated using suitable long-term rainfall variability drivers. Besides, the rainfall variability drivers can be used to predict an upcoming period of decrease or increase rainfall. Generally, the variation and changes in the climate system are tending to alter the frequency and severity of rainfall-based or water-based disasters in many parts of the world. For the case of Uganda, these results demonstrate the need to embrace the context of stationarity in hydrometeorology for planning, designing, operation, and management of risk-based water resources applications. 


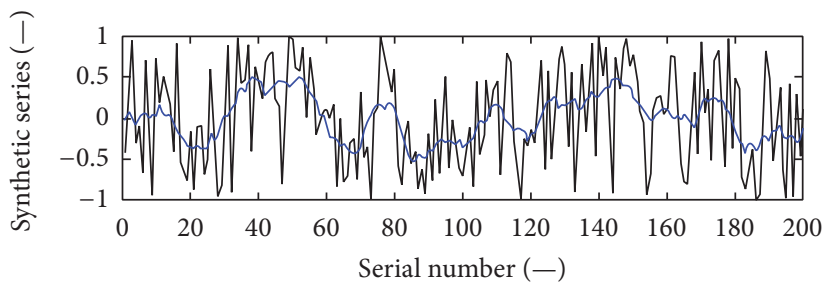

(a) Rescaled data and decadal anomaly

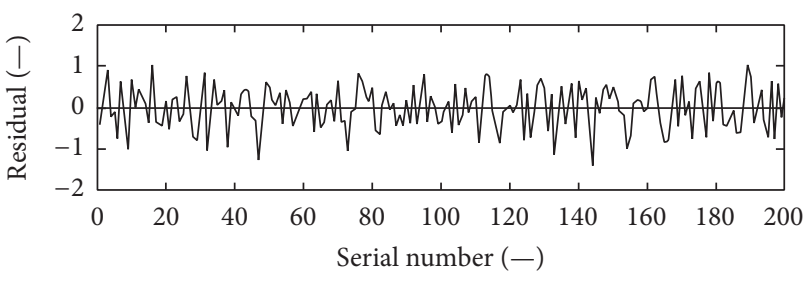

(b) Detrended series

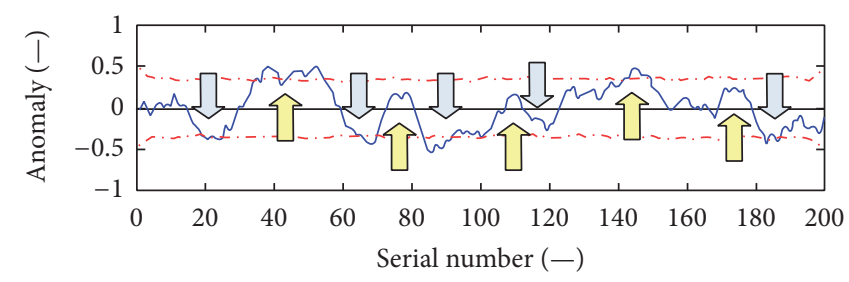

(c) Extracted variability and $95 \%$ confidence interval

FIGURE 10: NAIM results for (a) the decomposition of synthetic series, (b) detrending of the series, and (c) significance of the decadal anomalies in the series.

It is recommended that the insights from the findings as in this study be updated in the future, especially when long-term observed data become available or if the biases of the rainfall reanalyses datasets in reproducing historical extreme rainfall events reduce tremendously. Eventually, it would also be vital to conduct another detailed research to examine the geospatial differences in climate change impacts on rainfall extremes across the country. This could be done based on statistical downscaling of high-resolution global climate models to data series at grid cells covering the entire country as considered in this study.

\section{Appendix}

\section{A. Nonparametric Anomaly Indicator Method}

Before investigating the cyclical variation, the data should be detrended if it is characterized by monotonic trend. If the series has seasonal component, it should be first deseasonalized. On the contrary, if the data is dominated by cyclical fluctuations (i.e., when there is neither monotonic trend nor seasonal component) the series is used without detrending. According to [41], before the rescaling and convolution of the dataset with cyclical fluctuations, prewhitening of the series is done where necessary. In this study, prewhitening was done for series with significant lag-1 autocorrelation AR(1) process considering the significance level of $5 \%$. If the dataset which is free from the influence of autocorrelation is denoted by $X$ and another series $Y$ is obtained as the replica of $X$, the rescaled series $c$ can be given by $[27,28]$

$$
\begin{array}{r}
c_{i}=n-\sum_{j=1}^{n} \operatorname{sgn}_{2}\left(y_{j}-x_{i}\right)-2 \sum_{j=1}^{n} \operatorname{sgn}_{1}\left(y_{j}-x_{i}\right) \\
\qquad \text { for } i=1,2, \ldots, n,
\end{array}
$$

where

$$
\begin{aligned}
& \operatorname{sgn}_{1}\left(y_{j}-x_{i}\right)= \begin{cases}1 & \text { if }\left(y_{j}-x_{i}\right)>0 \\
0 & \text { if }\left(y_{j}-x_{i}\right) \leq 0\end{cases} \\
& \operatorname{sgn}_{2}\left(y_{j}-x_{i}\right) \\
& = \begin{cases}1 & \text { if }\left(y_{j}-x_{i}\right)=0 \\
0 & \text { if }\left(y_{j}-x_{i}\right)<0 \text { or }\left(y_{j}-x_{i}\right)>0 .\end{cases}
\end{aligned}
$$

The anomaly $\left(e_{k}\right)$ in $k$ th time slice of window length $d$ from the rescaled series $c$ can be computed based on temporal convolution using [39-41]

$$
e_{k}=\frac{1}{s_{k}(n-1)} \sum_{i=1+q}^{f} c_{i} \quad \text { for } 1 \leq k \leq n,
$$

where

$$
\begin{aligned}
& q= \begin{cases}0 & \text { if } k \leq w \\
k-w & \text { if } k>w\end{cases} \\
& f= \begin{cases}n & \text { if }(d+k-w) \geq n \\
d+k-w & \text { if }(d+k-w)<n,\end{cases} \\
& s_{k}= \begin{cases}d+k-w & \text { for } 1 \leq k<w \\
d & \text { for } w \leq k \leq(n-w) \\
n-k+w & \text { for }(n-w)<k \leq n .\end{cases}
\end{aligned}
$$

To assess decadal anomalies, $d$ was set to 10 years; thus, $w=5$. Figure 10 gives an illustration of the decadal anomalies based on synthetic series of $n=200$. In Figure 10(a), the decadal anomalies are also superimposed on the synthetic 
series for illustration of the convolution operation. Using the extracted structure, the dataset can be detrended to obtain the residual series (Figure 10(b)). In the plot of anomalies (Figure 10(c)), the horizontal line $e_{k}=0$ is taken as the reference and the anomalies above and below the reference represented by the upward and downward arrows, respectively, characterize the temporal variability.

Under the null hypothesis $H_{0}$ of natural randomness in the series, the bounds or thresholds for the rejection/acceptance of $H_{0}$ can be constructed in the form of percentile confidence intervals (CI) using the nonparametric bootstrapping based on Monte-Carlo simulations. In the first step, (A.4) is applied to the original series. Secondly, the temporal sequence of the given series is altered by reshuffling the dataset and again (A.4) applied to the new series. The second step is repeated several times, say $N_{\mathrm{MC}}$. In this study, the repetition was done for $N_{\mathrm{MC}}=10000$ so as to yield 10000 sets of anomalies. Considering the significance level of $\alpha \%$ and $i$ th observation, the set of anomalies derived from the second step is ranked from the highest to the lowest and the (100- $\alpha \%)$ CI upper and lower limits are obtained as $[0.005 \times$ $\left.\alpha \% \times N_{\mathrm{MC}}\right]$ th and $\left[\{1-(0.005 \times \alpha \%)\} \times N_{\mathrm{MC}}\right]$ th, respectively [27]. At the significance level of $\alpha \%$, if the (100- $\alpha \%) \mathrm{CI}$ limits are upcrossed or downcrossed by the anomalies from the original series (i.e., before reshuffling), $H_{0}$ is rejected; otherwise, $H_{0}$ is accepted. In the illustration, using $\alpha=5 \%$, $H_{0}$ (natural randomness) can be rejected (Figure 10(c)).

\section{B. Statistical CRD Trend Test}

To test for monotonic trend in the series, (A.1) is first applied to the original series. Eventually, the values of $c_{i}$ from (A.1) are transformed using $d_{i}=-1 \times c_{i}$ for $i=1,2, \ldots, n$ such that the trend statistic $T$ is computed using [42]

$$
T=\frac{6}{\left(n^{3}-n\right)} \sum_{i=1}^{n-1} \sum_{j=1}^{i} d_{j}
$$

The distribution of $T$ is approximately normal with the mean of zero and variance $\left(V_{1}\right)$ given by $[41,43]$

$$
V_{1}=\frac{1}{n-1}\left(1-\frac{10}{17} a^{2}-\frac{7}{17} a\right),
$$

where $a$ (B.3) is the measure of ties in the data

$$
a=\frac{-1}{n^{2}-n}\left(n-\sum_{i=1}^{n} \sum_{j=1}^{n} \operatorname{sgn}_{2}\left(y_{j}-x_{i}\right)\right)
$$

and $\operatorname{sgn}_{2}\left(y_{j}-x_{i}\right)$ is as defined in (A.3).

The standardized test statistic $Z$ which follows the standard normal distribution with mean (variance) of zero (one) is given by (B.4). An upward/downward monotonic trend is indicated by a positive/negative value of $T$. At the significance level $\alpha \%$, the null hypothesis $H_{0}$ (no trend) is accepted if $|Z|$ is less than the absolute value of the standard normal variate $Z_{\alpha / 2}$; otherwise $H_{0}$ is rejected. Alternatively, the $p$ value (probability value, $p$ ) can be used. In this case, $H_{0}$ is accepted if the $p$ value based on $|Z|$ is greater than the nominal $\alpha$.

$$
Z=\frac{T}{\sqrt{V_{2}}}
$$

where $V_{2}$ is $V_{1}$ corrected for the influence of long-term persistence [41] using the following steps:

(i) Estimate the linear trend slope $m$ using the method of [47, 48].

(ii) Using $m$ from Step (i), detrend the original series.

(iii) Approximate $H$ using the detrended series from Step (ii) in terms of the generalized Hurst exponent $H\left(q^{\#}\right)$ based on the scaling of renormalized $q^{\#}$-moments of the distribution [52-55]. Alternatively, $H$ can be computed using (B.5) based on the autocorrelation function for fractional Gaussian noise model given by [53]

$r_{k}=0.5 \times\left(|k+1|^{2 H}-2|k|^{2 H}+|k-1|^{2 H}\right)$,

where $r_{k}$ is lag- $k$ serial correlation coefficient computed based on the detrended series from Step (ii). For instance, when $k=1$ from (B.5), $H$ can be given by

$$
H=0.5 \times\left(1+\frac{\ln \left(r_{1}+1\right)}{\ln (2)}\right) .
$$

(iv) If $H \leq 0.5$, take $V_{2}$ as $V_{1}$ from (B.2); otherwise, compute the test statistic variance corrected from the influence of long-term persistence using [41]

$$
V_{2}=V_{1} \times b n^{a}
$$

where $b=1.55490-1.20344 H-0.27340 H^{2}$ and $a=$ $-0.62304+0.87827 H+0.82220 H^{2}$.

\section{Competing Interests}

The author declares that there is no competing interests regarding the publication of this paper.

\section{Acknowledgments}

The gridded rainfall data used were based on the Princeton Global Forcings obtained online from http://hydrology .princeton.edu/data/pgf/ [accessed on 12-02-2016].

\section{References}

[1] S. Shahid, "Trends in extreme rainfall events of Bangladesh," Theoretical and Applied Climatology, vol. 104, no. 3-4, pp. 489499, 2011.

[2] W. Z. Wan Zin, S. Jamaludin, S. M. Deni, and A. A. Jemain, "Recent changes in extreme rainfall events in Peninsular Malaysia: 1971-2005," Theoretical and Applied Climatology, vol. 99, no. 3-4, pp. 303-314, 2010. 
[3] D. Burić, J. Luković, B. Bajat, M. Kilibarda, and N. Živković, "Recent trends in daily rainfall extremes over Montenegro (1951-2010)," Natural Hazards and Earth System Sciences, vol. 15, no. 9, pp. 2069-2077, 2015.

[4] Y. Hundecha and A. Bárdossy, "Trends in daily precipitation and temperature extremes across western Germany in the second half of the 20th century," International Journal of Climatology, vol. 25, no. 9, pp. 1189-1202, 2005.

[5] M. Q. Villafuerte, J. Matsumoto, I. Akasaka, H. G. Takahashi, H. Kubota, and T. A. Cinco, "Long-term trends and variability of rainfall extremes in the Philippines," Atmospheric Research, vol. 137, pp. 1-13, 2014.

[6] Q. You, S. Kang, E. Aguilar, and Y. Yan, "Changes in daily climate extremes in the eastern and central Tibetan Plateau during 19612005," Journal of Geophysical Research Atmospheres, vol. 113, no. D7, 2008.

[7] I. Keggenhoff, M. Elizbarashvili, A. Amiri-Farahani, and L. King, "Trends in daily temperature and precipitation extremes over Georgia, 1971-2010," Weather and Climate Extremes, vol. 4, pp. 75-85, 2014.

[8] M. New, B. Hewitson, D. B. Stephenson et al., "Evidence of trends in daily climate extremes over southern and west Africa," Journal of Geophysical Research, vol. 111, no. 14, 2006.

[9] R. C. Balling Jr., M. S. K. Kiany, S. S. Roy, and J. Khoshhal, "Trends in extreme precipitation indices in Iran: 1951-2007," Advances in Meteorology, vol. 2016, Article ID 2456809, 8 pages, 2016.

[10] T. C. Peterson, "Recent changes in climate extremes in the Caribbean region," Journal of Geophysical Research, vol. 107, article 4601, 2002.

[11] M. Kamruzzaman, S. Beecham, and A. V. Metcalfe, "Estimation of trends in rainfall extremes with mixed effects models," Atmospheric Research, vol. 168, pp. 24-32, 2016.

[12] B. Asadieh and N. Y. Krakauer, "Global trends in extreme precipitation: climate models versus observations," Hydrology and Earth System Sciences, vol. 19, no. 2, pp. 877-891, 2015.

[13] V. V. Kharin, F. W. Zwiers, X. Zhang, and G. C. Hegerl, "Changes in temperature and precipitation extremes in the IPCC ensemble of global coupled model simulations," Journal of Climate, vol. 20, no. 8, pp. 1419-1444, 2007.

[14] L. V. Alexander, X. Zhang, T. C. Peterson et al., "Global observed changes in daily climate extremes of temperature and precipitation," Journal of Geophysical Research, vol. 111, Article ID D05109, 2006.

[15] T. Iwashima and R. Yamamoto, "A statistical analysis of the extreme events: long-term trend of heavy daily precipitation," Journal of the Meteorological Society of Japan, vol. 71, no. 5, pp. 637-640, 1993.

[16] L. Jacobs, O. Dewitte, J. Poesen et al., "Landslide characteristics and spatial distribution in the Rwenzori Mountains, Uganda," Journal of African Earth Sciences, 2016.

[17] A. Knapen, M. G. Kitutu, J. Poesen, W. Breugelmans, J. Deckers, and A. Muwanga, "Landslides in a densely populated county at the footslopes of Mount Elgon (Uganda): characteristics and causal factors," Geomorphology, vol. 73, no. 1-2, pp. 149-165, 2006.

[18] C. Onyutha and P. Willems, "Spatial and temporal variability of rainfall in the Nile Basin," Hydrology and Earth System Sciences, vol. 19, no. 5, pp. 2227-2246, 2015.

[19] J. Phillips and B. McIntyre, "ENSO and interannual rainfall variability in Uganda: implications for agricultural management,"
International Journal of Climatology, vol. 20, no. 2, pp. 171-182, 2000.

[20] C. Onyutha, H. Tabari, M. T. Taye, G. N. Nyandwaro, and P. Willems, "Analyses of rainfall trends in the Nile River Basin," Journal of Hydro-Environment Research, vol. 13, pp. 36-51, 2016.

[21] J. E. Diem, S. J. Ryan, J. Hartter, and M. W. Palace, "Satellitebased rainfall data reveal a recent drying trend in central equatorial Africa," Climatic Change, vol. 126, no. 1-2, pp. 263272, 2014.

[22] M. K. Kansiime, S. K. Wambugu, and C. A. Shisanya, "Perceived and actual rainfall trends and variability in eastern uganda: implications for community preparedness and response," Journal of Natural Sciences Research, vol. 3, pp. 179-194, 2013.

[23] F. N. W. Nsubuga, J. M. Olwoch, C. J. W. Rautenbach, and O. J. Botai, "Analysis of mid-twentieth century rainfall trends and variability over southwestern Uganda," Theoretical and Applied Climatology, vol. 115, no. 1-2, pp. 53-71, 2014.

[24] M. Kizza, A. Rodhe, C.-Y. Xu, H. K. Ntale, and S. Halldin, "Temporal rainfall variability in the Lake Victoria Basin in East Africa during the twentieth century," Theoretical and Applied Climatology, vol. 98, no. 1, pp. 119-135, 2009.

[25] C. J. Schreck III and F. H. M. Semazzi, "Variability of the recent climate of eastern Africa," International Journal of Climatology, vol. 24, no. 6, pp. 681-701, 2004.

[26] P. Nyeko-Ogiramoi, P. Willems, and G. Ngirane-Katashaya, "Trend and variability in observed hydrometeorological extremes in the Lake Victoria basin," Journal of Hydrology, vol. 489, pp. 56-73, 2013.

[27] J. Sheffield, G. Goteti, and E. F. Wood, "Development of a 50year high-resolution global dataset of meteorological forcings for land surface modeling," Journal of Climate, vol. 19, no. 13, pp. 3088-3111, 2006.

[28] R. Zeng and X. Cai, "Climatic and terrestrial storage control on evapotranspiration temporal variability: analysis of river basins around the world," Geophysical Research Letters, vol. 43, no. 1, pp. 185-195, 2016.

[29] A. Hoell, S. Shukla, M. Barlow, F. Cannon, C. Kelley, and C. Funk, "The forcing of monthly precipitation variability over Southwest Asia during the Boreal Cold Season," Journal of Climate, vol. 28, no. 18, pp. 7038-7056, 2015.

[30] E. Kalnay, M. Kanamitsu, R. Kistler et al., "The NCEP/NCAR 40-year reanalysis project," Bulletin of the American Meteorological Society, vol. 77, no. 3, pp. 437-471, 1996.

[31] U. Ehret, E. Zehe, V. Wulfmeyer, K. Warrach-Sagi, and J. Liebert, "HESS Opinions 'should we apply bias correction to global and regional climate model data?"' Hydrology and Earth System Sciences, vol. 16, no. 9, pp. 3391-3404, 2012.

[32] C. Miao, H. Ashouri, K.-L. Hsu, S. Sorooshian, and Q. Duan, "Evaluation of the PERSIANN-CDR daily rainfall estimates in capturing the behavior of extreme precipitation events over China," Journal of Hydrometeorology, vol. 16, no. 3, pp. 13871396, 2015.

[33] C. Onyutha and P. Willems, "Influence of spatial and temporal scales on statistical analyses of rainfall variability in the River Nile basin," Dynamics of Atmospheres and Oceans, vol. 77, pp. 26-42, 2017.

[34] C. Onyutha and P. Willems, "Uncertainty in calibrating generalised Pareto distribution to rainfall extremes in Lake Victoria basin," Hydrology Research, vol. 46, no. 3, pp. 356-376, 2015. 
[35] P. D. Jones, T. Jonsson, and D. Wheeler, "Extension to the North Atlantic Oscillation using early instrumental pressure observations from gibraltar and south-west Iceland," International Journal of Climatology, vol. 17, no. 13, pp. 1433-1450, 1997.

[36] N. A. Rayner, D. E. Parker, E. B. Horton et al., "Global analyses of sea surface temperature, sea ice, and night marine air temperature since the late nineteenth century," Journal of Geophysical Research, vol. 108, Article ID D1427, 2003.

[37] K. E. Trenberth, “The definition of El Niño," Bulletin of the American Meteorological Society, vol. 78, no. 12, pp. 2771-2777, 1997.

[38] J. E. Tierney, J. E. Smerdon, K. J. Anchukaitis, and R. Seager, "Multidecadal variability in East African hydroclimate controlled by the Indian Ocean," Nature, vol. 493, no. 7432, pp. 389392, 2013.

[39] C. Onyutha, "Variability of seasonal and annual rainfall in the River Nile riparian countries and possible linkages to oceanatmosphere interactions," Hydrology Research, vol. 47, no. 1, pp. 171-184, 2016

[40] C. Onyutha, "Influence of hydrological model selection on simulation of moderate and extreme flow events: A Case Study of the Blue Nile Basin," Advances in Meteorology, vol. 2016, Article ID 7148326, 28 pages, 2016.

[41] C. Onyutha, "Statistical uncertainty in hydrometeorological trend analyses," Advances in Meteorology, vol. 2016, Article ID 8701617, 26 pages, 2016.

[42] C. Onyutha, "Identification of sub-trends from hydrometeorological series," Stochastic Environmental Research and Risk Assessment, vol. 30, no. 1, pp. 189-205, 2016.

[43] C. Onyutha, "Statistical analyses of potential evapotranspiration changes over the period 1930-2012 in the Nile River riparian countries," Agricultural and Forest Meteorology, vol. 226-227, pp. 80-95, 2016.

[44] J. D. Horel, "Complex principal component analysis: theory and examples," Journal of Climate and Applied Meteorology, vol. 23, no. 12, pp. 1660-1673, 1984.

[45] M. B. Richman, "Rotation of principal components," Journal of Climatology, vol. 6, no. 3, pp. 293-335, 1986.

[46] H. F. Kaiser, "The varimax criterion for analytic rotation in factor analysis," Psychometrika, vol. 23, no. 3, pp. 187-200, 1958.

[47] H. Theil, "A rank-invariant method of linear and polynomial regression analysis," Nederlandse Akademie van Wetenschappen, Series A, vol. 53, pp. 386-392, 1950.

[48] P. K. Sen, "Estimates of the regression coefficient based on Kendall's tau," Journal of the American Statistical Association, vol. 63, pp. 1379-1389, 1968.

[49] M. Kendall, Multivariate Analysis, Charles Griffin, 1980.

[50] S. E. Nicholson and J. Kim, "The relationship of the El NinoSouthern Oscillation to African rainfall," International Journal of Climatology, vol. 17, no. 2, pp. 117-135, 1997.

[51] F. N. W. Nsubuga, J. M. Olwoch, C. J. W. de Rautenbach, and O. J. Botai, "Analysis of mid-twentieth century rainfall trends and variability over southwestern Uganda," Theoretical and Applied Climatology, vol. 115, no. 1-2, pp. 53-71, 2014.

[52] T. Di Matteo, T. Aste, and M. M. Dacorogna, "Scaling behaviors in differently developed markets," Physica A: Statistical Mechanics and Its Applications, vol. 324, no. 1-2, pp. 183-188, 2003.

[53] B. Mandelbrot, "Une classe de processus stochastiques homothetiques a soi: application a la loi climatologique de H.E. Hurst," Comptes Rendus de l'Académie des Sciences, vol. 260, pp. 32743276, 1965.
[54] T. Di Matteo, T. Aste, and M. M. Dacorogna, "Long-term memories of developed and emerging markets: using the scaling analysis to characterize their stage of development," Journal of Banking \& Finance, vol. 29, no. 4, pp. 827-851, 2005.

[55] T. Di Matteo, "Multi-scaling in finance," Quantitative Finance, vol. 7, no. 1, pp. 21-36, 2007. 

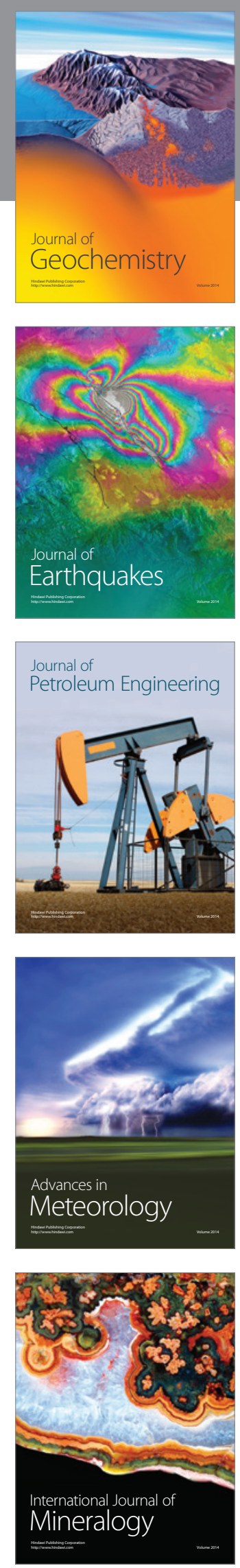
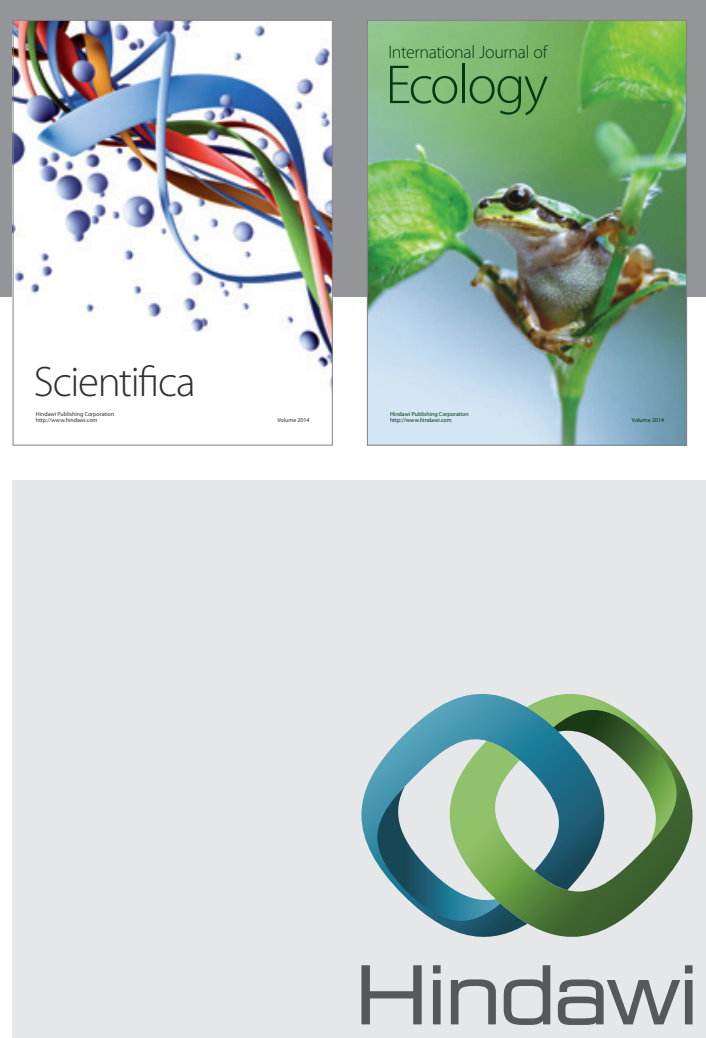

Submit your manuscripts at

http://www.hindawi.com
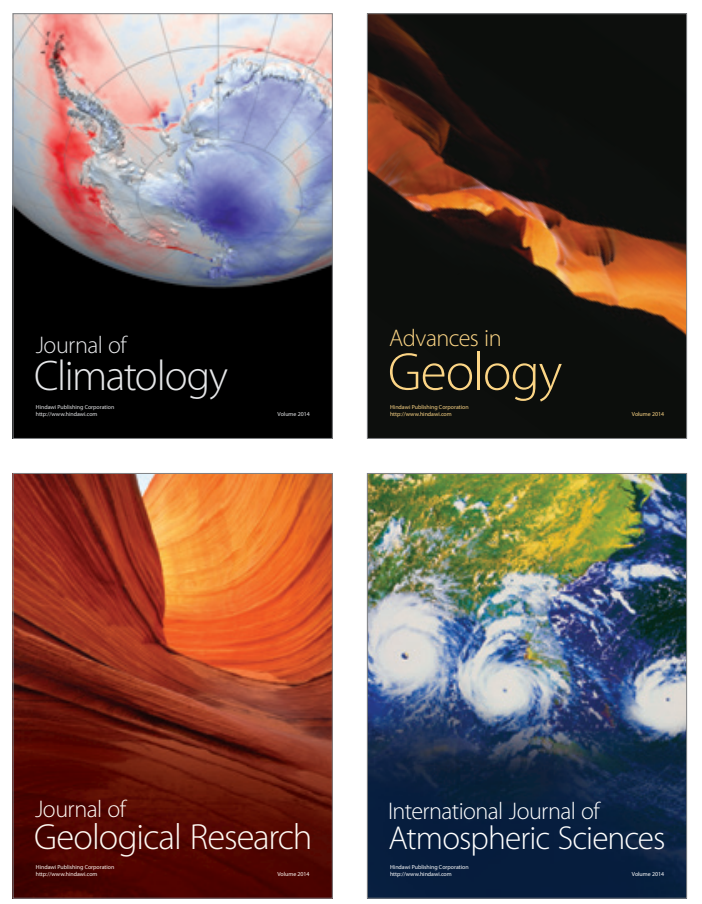

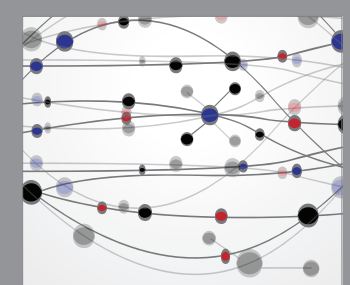

The Scientific

\section{World Journal}
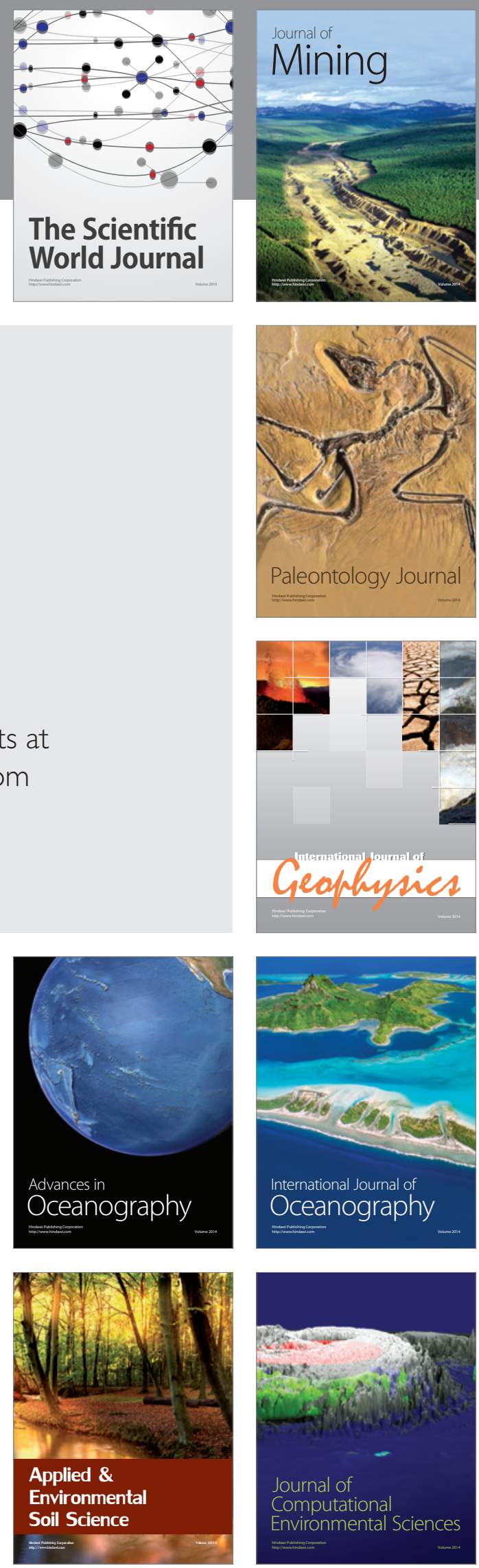